\title{
ASSESSMENT OF THE EFFECTS OF THE ZUIDER SEA CLOSURE ON THE HYDRODYNAMICS OF THE WADDEN SEA INLETS
}

\author{
Julia Vroom ${ }^{1}$, Edwin Elias $^{1}$, Jamie Lescinski $^{1}$ and Zheng Bing Wang ${ }^{1,2}$
}

\begin{abstract}
Large hydrodynamic and morphodynamic changes have taken place in the western Dutch Wadden Sea due to the closure of the Zuider Sea in the early 1930s. Hydrodynamic simulations for three situations, viz. just before the closure, just after the closure and at present, have been carried out in order to investigate the hydrodynamic changes since the closure and to improve our understanding of the observed morphodynamic changes. The model results show a large increase in tidal range after the closure of the Zuider Sea. This increase continued to grow after the closure due to bathymetric change and sea level rise. The morphodynamic analysis focuses on the changed behavior of the ebb-tidal deltas of the Texel Inlet and the Vlie Inlet. Both ebb-tidal deltas have undergone a re-orientation in up-drift direction. Two possible explanations based on the literature for this change are discussed with the help of the hydrodynamic simulations.
\end{abstract}

Keywords: Wadden Sea, Zuider Sea, Delft3D modeling, tidal basins, basin area reduction, tidal asymmetry

\section{INTRODUCTION}

The Wadden Sea stretches along the northwest coasts of the Netherlands (Fig. 1) and Germany. This sea is composed of a series of tidal basins which are sheltered from waves from the North Sea by barrier islands. The tide is propagating from Texel inlet in the west towards the German Bight in the east. Along the Dutch coast, the tidal range increases from $1.4 \mathrm{~m}$ at Den Helder (southwest corner of the Wadden Sea) to approximately $1.9 \mathrm{~m}$ at the Amelander inlet.

The Texel inlet is relatively young and formed in the $10^{\text {th }}$ century. Prior to this, the Vlie channel formed the connection between the North Sea and a large inland lake, which later became the Zuider Sea. From the beginning, the Texel inlet grew in size with a corresponding increase in tidal prism of the Wadden Sea. This was enhanced by the closing of smaller channels through the construction of dikes, and an increase in basin area due to the flooding of vulnerable peat areas (Sha, 1989: Oost and Kleine Punte, 2004). Since the $16^{\text {th }}$ century, and until the closure of the Zuider Sea, the Texel inlet's ebb-tidal delta has shown a cyclic behavior, with a clockwise rotating system, consisting of a main channel and shoals, which merged with the island of Texel. In total, four cycles have been completed (Sha, 1989). The Vlie inlet also had a cyclic ebb-tidal delta behavior until the closure of the Zuider Sea (Sha, 1989).

A large flood in 1916 motivated the construction of a closure dam to protect the land surrounding the Zuider Sea from flooding and to create a fresh water lake, Lake Ijssel (Fig.1). The closure dam, the 'Afsluitdijk', reduced the Zuider Sea coastline by a length of more than $200 \mathrm{~km}$ and the surface area of the open basin from $5200 \mathrm{~km}^{2}$ to $1500 \mathrm{~km}^{2}$ (Rietveld, 1963).

The plans for the enclosure of the Zuider Sea existed already for some decades and introduced a lot of discussion about the expected changes in hydrodynamics. The State Committee Lorentz was appointed in 1918 and had the task to predict the changes in tidal propagation and storm surge levels in the Wadden Sea due to the enclosure of the Zuider Sea. For this purpose, the Wadden Sea was schematized by a network of channels. Only the $\mathrm{M}_{2}$ constituent was used to represent the tidal characteristics and linear friction was taken into account (Lorentz, 1926). The committee predicted a large increase in the tidal range throughout the basins, but also in the flow velocities through the inlets. The committee recommended a small adaptation in the position of the dam, northward of the original proposed location, to minimize the anticipated increases in flow velocities through the tidal inlets (Klok and Schalkers, 1980). These predictions have proven to be correct (Rietveld, 1962; Elias et al., 2003). Reflection by the Afsluitdijk causes that the tidal ranges increased in the Wadden Sea As a consequence the tidal prism increased as well despite the reduced basin area.

The closure of the Zuider Sea also resulted in large morphological changes (Elias et al., 2003; Elias and Van der Spek: 2006, Elias et al., 2012), which had not been sufficiently predicted before the closure. Based on the bathymetric data since around 1927 Elias et al. (2012) present an evaluation of the morphological developments of the Dutch Wadden Sea. It is shown that even today, the morphology in the Western Wadden Sea is still adapting to the closure of the Zuider Sea (Elias,

\footnotetext{
${ }^{1}$ Deltares, P.O. Box 177, 2600 MH Delft, The Netherlands

${ }^{2}$ Delft University of Technology, Faculty of Civil Engineering and Geosciences, Delft
} 
2006). Despite the increase of the tidal prism of the Texel Inlet, a large amount of sediment has been transported from the ebb-tidal delta to the tidal basin of this inlet, which is seemingly in contradiction with the general theory. An increase of the tidal prism would generally result in an increase of the ebb-tidal delta volume (Walton and Adams, 1976) and larger channels in the basin corresponding to sediment surplus. However, according to Elias et al. (2003, 2012), the ebb-tidal deltas of Texel and Vlie inlet are shrinking due to the sand demand in the inner parts of the basins near the closure dam. Sedimentation in the basins has taken place in the channels close to the Afsluitdijk, in the channel connecting Marsdiep (channel directly north of Den Helder) to Vlie and in the back of the Vlie basin (Fig. 1). It is also concluded that the Texel and Vlie basins cannot be seen as individual basins (Elias, 2006). Exchange of water and sediments takes place over the tidal divide between Texel and Vlie basin, and more importantly, the location of the tidal divide is not fixed but is moving such that the Texel basin becomes larger at the cost of the Vlie basin. The ebb-tidal deltas of Texel and Vlie basin are not only reducing in volume, but have undergone a re-orientation in up-drift direction in relation to the tide progation (?); i.e. towards the south for the Texel Inlet and towards the southwest for the Vlie Inlet, as well (Fig. 1). Up to present, the up-drift orientation of the two ebb-tidal deltas remains, despite the observed cyclic behavior of the ebb-tidal deltas prior to closure (Sha, 1989).

The aim of the current study is to improve our understanding of the observed morphological development due to the closure of the Zuider Sea as described by Elias et al. (2012). This paper focuses on the development of the ebb-tidal deltas of the Texel and Vlie inlets, focusing on the change in main channel orientation.

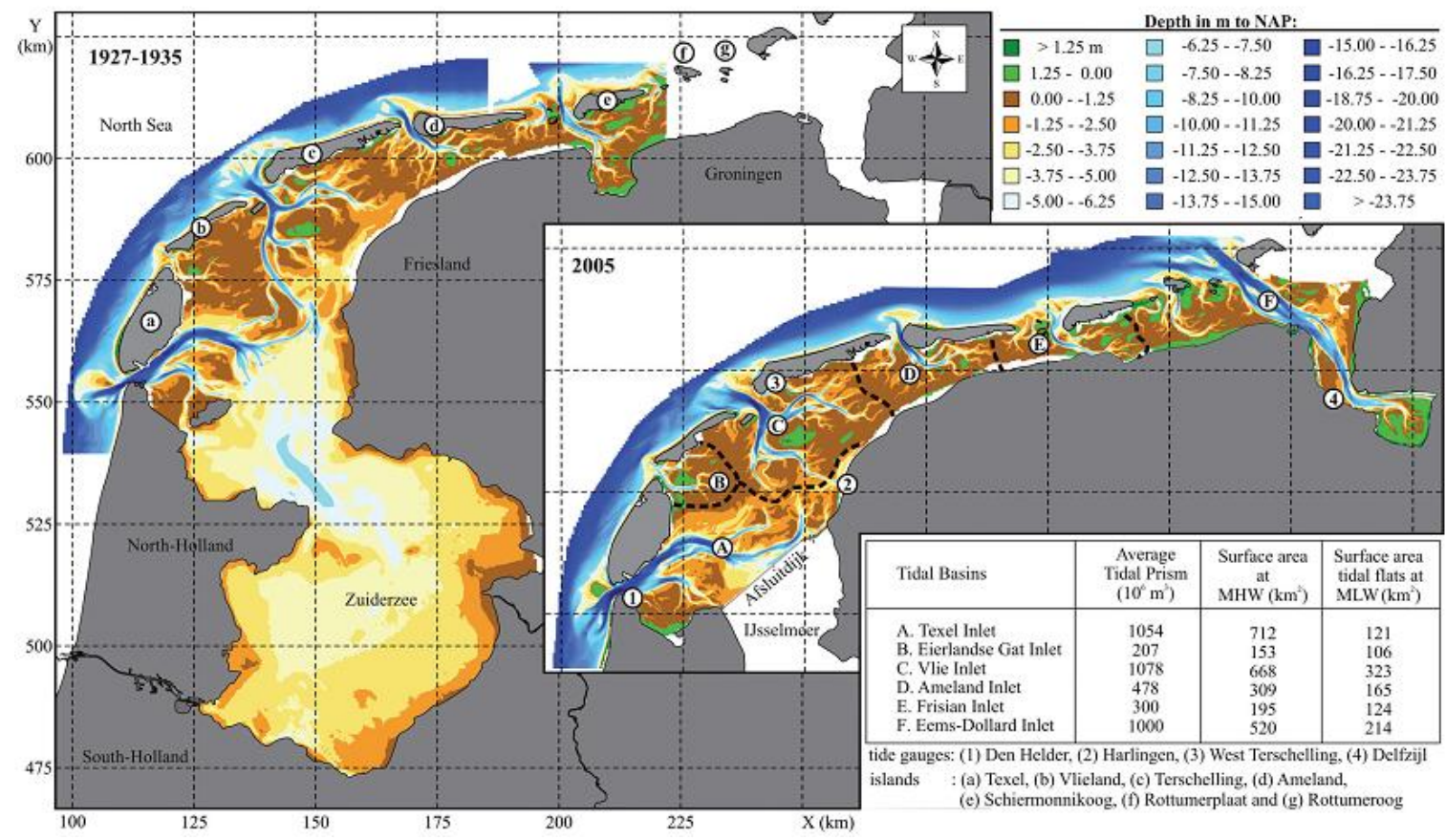

Figure 1. Bathymetry in $1927 / 35$ and 2005. Main characteristics of the individual inlets for the present situation are listed in the table and based on Louters \& Gerritsen (1994). (Elias et al. 2012).

\section{APPROACH}

\section{General approach}

For explaining the changed behavior of the ebb-tidal deltas of the inlets Texel and Vlie two hypotheses have been postulated based on literature:

1. The orientation of the ebb-tidal deltas has changed as a result of the difference between propagation of the tide through the inlets versus the tidal propagation in the North Sea (Sha, 1989). The size and shape of ebb-tidal deltas is dependent upon the tidal prism and the degree of wave exposure (Hayes, 1979; Oertel, 1988; Sha, 1989). The orientation of ebb-tidal deltas with a large tidal prism, compared to the wave action, will generally be dependent upon the propagation of the tide on the seaside versus tidal flow through the inlet. According to Sha (1989), the orientation of the Texel inlet is due to the phase difference between the flow through the inlets 
versus the flow at the seaside of the basins. This phase difference is affected by the closure of the Zuider Sea, which might explain the re-orientation of the ebb-tidal delta.

2. The changes in the orientation of the ebb-tidal delta are the result of a change in the centre of gravity of the basins (Elias and Van der Spek, 2006). When the center of gravity of the basins changes, the steering of the flow from the inside of the basins to the inlets changes. In other words, the ebb flow direction towards the inlets changes.

These two hypotheses are tested by doing hydrodynamic modeling for three situations, viz. just before the closure, just after the closure and the recent situation. The changes in hydrodynamics are studied by analyzing the changes in tidal ranges, tidal prisms and flow velocity patterns within the Wadden Sea. The mean tidal range is defined as the difference between the mean high water level and the mean low water level. The maximum tidal range is defined as the difference between the maximum water level and the minimum water level occurring during the simulation period (note that this definition can lead to an overestimate of the maximum tidal range, but is suitable for the relative comparison between the three situations presented here). The flow through the inlets and on the ebbtidal delta is studied in more detail by analyzing flow patterns, which gives insight in both the phase shift between the shore parallel currents and the currents through the inlets, as well as the changes in flow patterns within the basins.

\section{Model setup}

A depth-averaged Delft3D-FLOW model is set-up to perform this hydrodynamic investigation. With this model, three different scenarios are studied. The pre-closure situation $(\sim 1926)$ includes the historical bathymetry which is constructed from digitalized historical maps (Fig. 2). The post-closure scenario uses a model resembling the situation just after closure ( 1933). Its bathymetry is equal to the pre-closure situation, but includes the closure dam. The third scenario represents the present situation and uses a 2005 bathymetry constructed of Jarkus and Vaklodingen data (Fig. 1). The computational grid has a resolution of approximately $250 \times 250 \mathrm{~m}$ in the Texel inlet and increases to 2 x $2 \mathrm{~km}$ at the offshore boundary (Fig. 2). At the open boundaries, a set of tidal constituents $\left(\mathrm{M}_{2}, \mathrm{~S}_{2}\right.$, $\mathrm{N}_{2}, \mathrm{~K}_{2}, \mathrm{~K}_{1}, \mathrm{O}_{1}, \mathrm{P}_{1}, \mathrm{Q}_{1}, \mathrm{M}_{\mathrm{F}}, \mathrm{MM}, \mathrm{M}_{4}, \mathrm{MS}_{4}, \mathrm{MN}_{4}$ and $\mathrm{M}_{6}$ ) is applied, which is based upon the TOPEXPoseidon (TPXO 7.2) data set (Egbert et al. 1994, Egbert and Erofeeva, 2004).

A tidal analysis of the observed water levels in July 2003 at the Terschelling Noordzee and Texel Noordzee stations has been used to calibrate the modeled tidal constituents. The difference between the model predictions and the observations, between the two observation stations, is averaged and equally applied to the boundaries. Detailed water level observations are not available to calibrate the pre-closure boundary conditions, therefore, the same set of calibrated tidal constituents from the 2003 model is applied to all three scenarios. The historical water level data does provide information on mean annual high and low water levels, which has been used to verify the two historical models. In this way, the model is calibrated using two stations outside the tidal basins and the performance of the model is verified using several stations inside the basins.

\section{Model Verification}

Comparison of the mean high water levels, mean low water level and tidal ranges between the three situations are shown in Fig. 3. In Fig. 2, the location of each of the water level stations is indicated. For the pre-closure (1926) and post-closure (1933) situations, a uniform correction of the still water level of $10 \mathrm{~cm}$ has been applied to correct for sea-level rise. This correction is within the range of a 12 to $14 \mathrm{~cm} /$ century sea-level rise, which has been observed for the Wadden Sea (Elias et al. 2012). The tidal levels simulated by the model compare reasonably well with the observed annual water levels. The deviation of the modeled water level from the observations is primarily due to meteorological effects, which are on the order of $5-6 \mathrm{~cm}$ when the water levels are averaged over a year.

In 2001, a flood discharge of $1010 \mathrm{~m}^{3} / \mathrm{s}$ and an ebb-discharge of $1115 \mathrm{~m}^{3} / \mathrm{s}$ have been measured in the Texel Inlet (Blok and Mol, 2001), which compares reasonably well with the computed tidal prism (Table 1). However, the model slightly under-predicts the difference between ebb and flood discharge. The modeled 2005 average tidal prism also compares well with the work of Louters and Gerritsen (1994). 


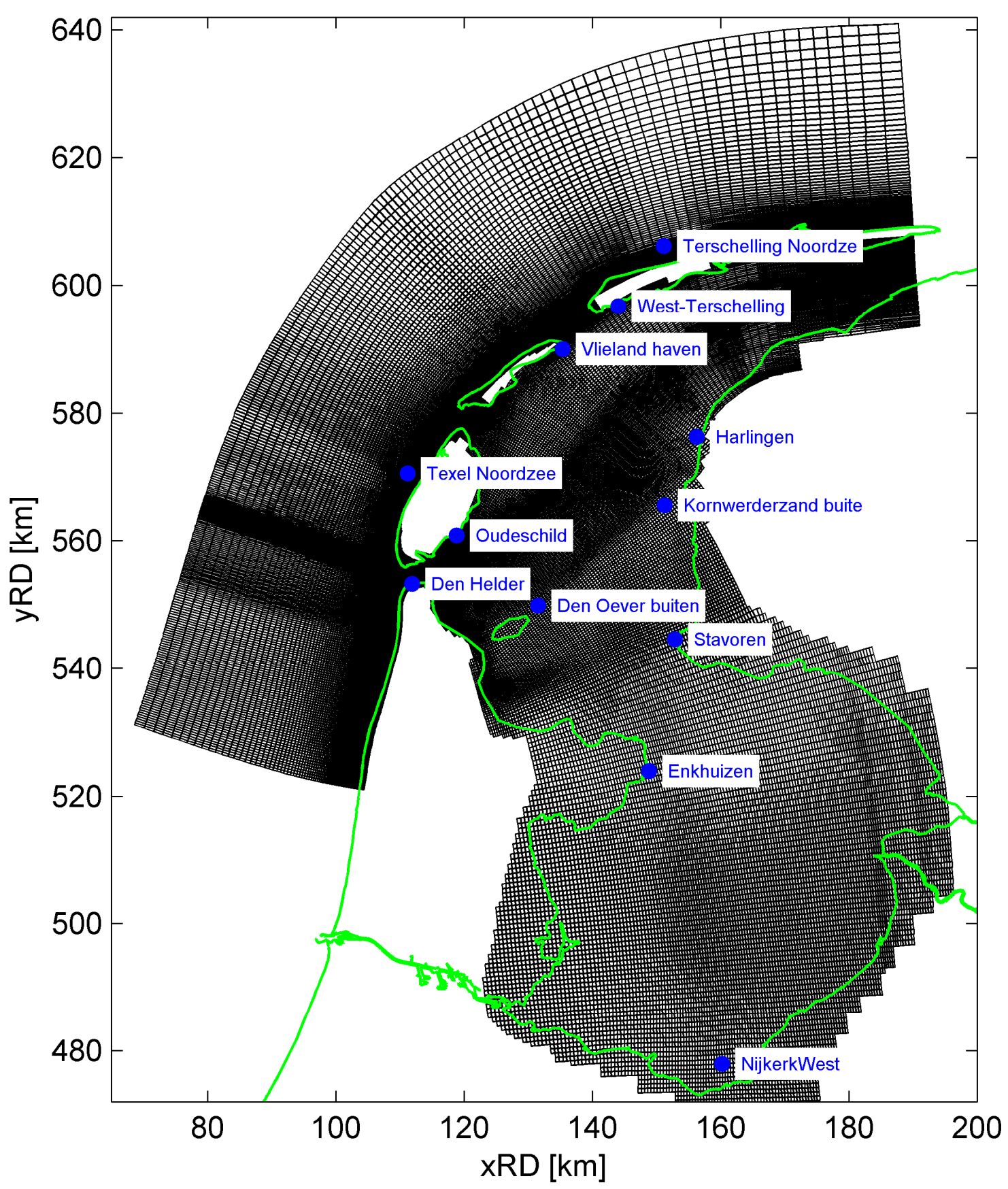

Figure 2. Computational grid and location of water level stations, and pre-closure bathymetry. 

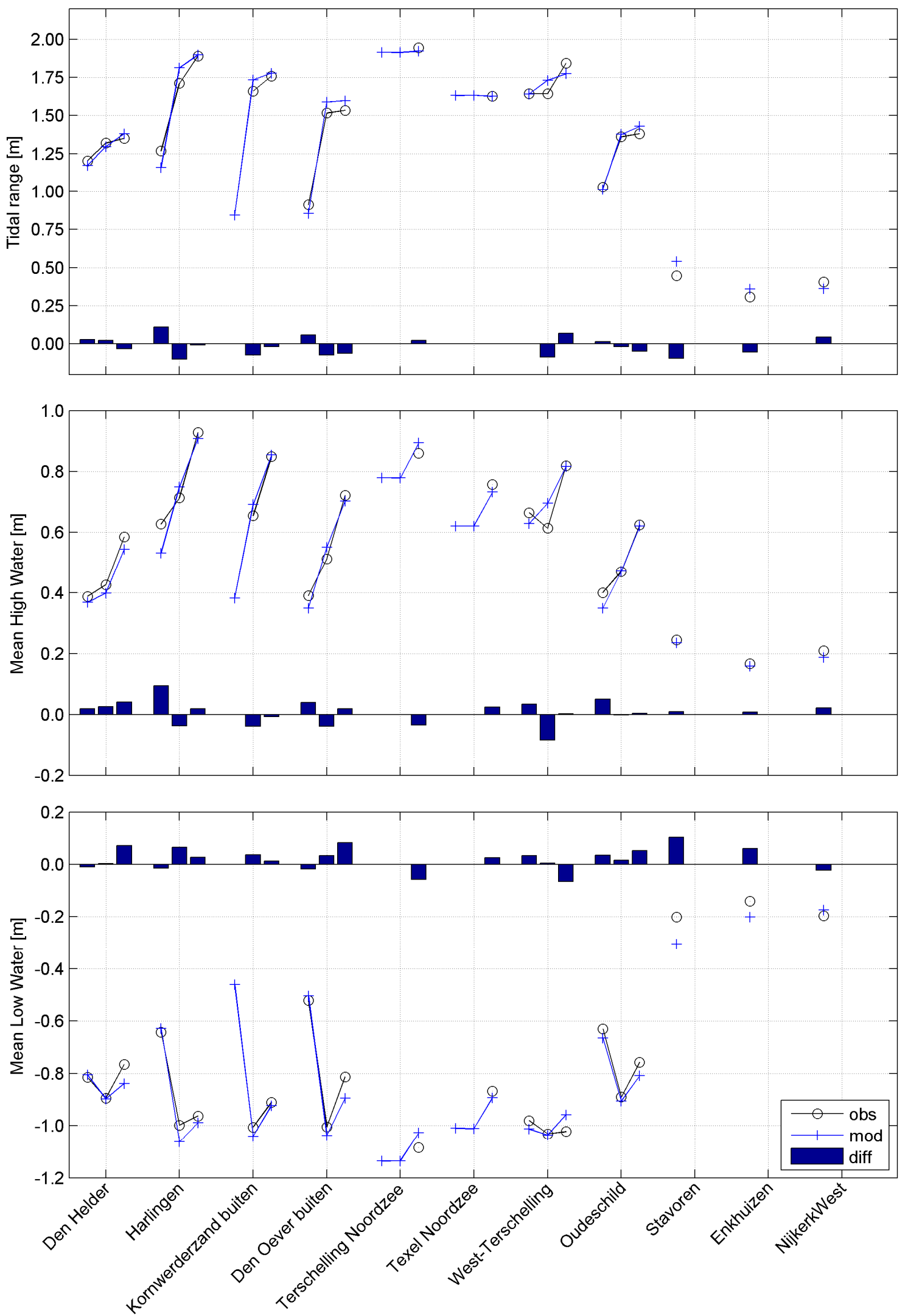

Figure 3. Tidal range, mean high water and mean low water levels for model and observations, for each station: pre-closure situation, post-closure situation and 2005 situation. 


\section{RESULTS}

\section{Tidal ranges}

The largest predicted changes in tidal levels are within the Texel basin for the stations Den Oever, Kornwerderzand, and Harlingen, which are adjacent to the Afsluitdijk (Fig. 3). The results also show that the increasing tidal levels due to the closure continued to change after 1933, likely due to the closure-induced morphological evolution, as well as sea level rise.

Figure 4 presents the spatial distribution of changes in tidal range. The figure shows the difference in the maximum tidal range and represents the tidal wave envelope. The difference between the pre and post-closure levels illustrate how the tidal range close to the Afsluitdijk has increased. Between 1933 and 2003, the largest changes in tidal ranges are in the Eierlandse Gat basin. This is likely caused by a deepening of the channels in the basin (Fig. 1) in combination with sea level rise, which deepens the water depth in the relatively shallow basin. In the Texel and Vlie basin, an increase in the tidal range is also predicted, albeit smaller than in the Eierlandse Gat basin. This is still not fully understood as the bathymetric changes caused the basins became shallower on average despite the rising sea level.
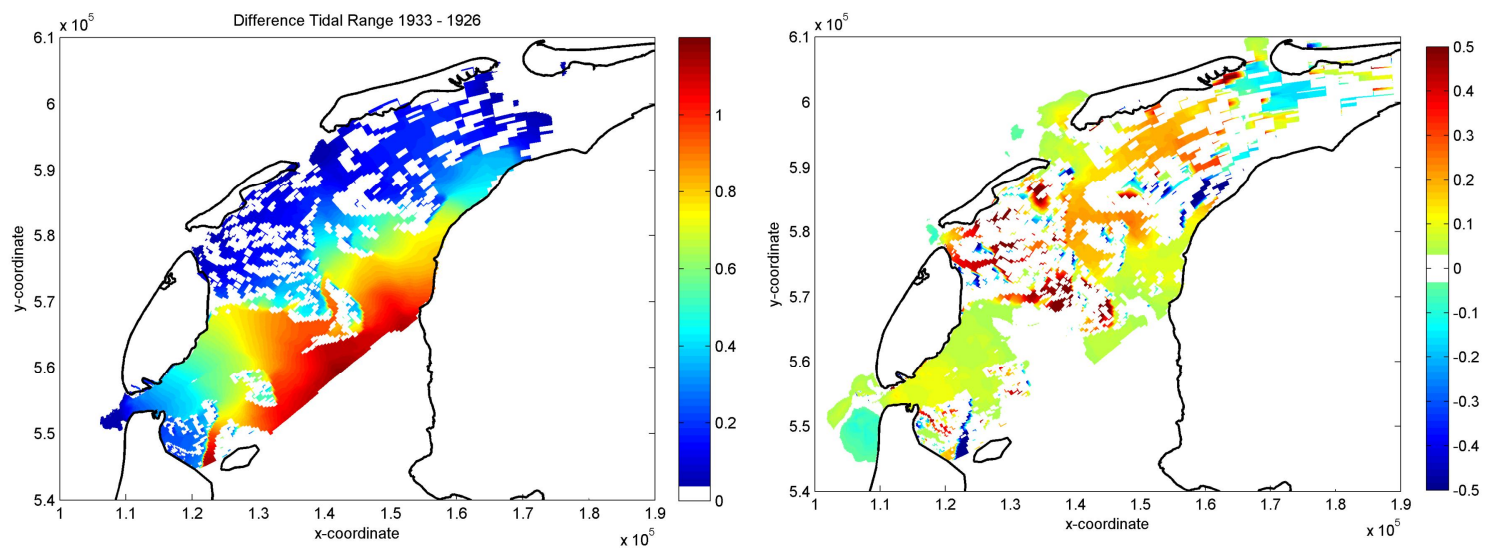

Figure 4. Difference in maximum tidal range, between 1926 and 1933 (left panel) and between 1933 and 2003 (right panel).

\section{Tidal Prisms}

The increase in tidal range and the reduction of the basin area also had a large effect on the tidal prisms. The tidal prisms for each of the three inlets are listed in table 1. A distinction between inflow and outflow has been made, providing information on exchange between the basins.

For all three inlets, we see an increase in tidal prism, which corresponds with an increase in tidal range, as indicated in Fig. 4. There is a 14\% increase in tidal prism in the Texel inlet between 1926 and 2005. At the Vlie inlet, the increase in tidal range was 14\%. At the Texel inlet, a net outflow of water occurs in all three scenarios. This outflow at the Texel inlet is balanced by the net inflow at the Vlie inlet. In the Eierlandse Gat, the tidal prism increased by approximately 44\% between 1926 and 2005, and inflow and outflow are in balance. The increase in Eierlandse Gat tidal prism is comparatively large and is a result of the increase in tidal range (Fig. 3). The difference between flood and ebb discharge is reduced between 1926 and 1933 for all three inlets. The tidal volumes transported over the tidal divide, behind Terschelling, are listed to illustrate that relatively small discharges take place over this tidal divide.

\begin{tabular}{|c|c|c|c|c|}
\hline \multicolumn{5}{|c|}{$\begin{array}{l}\text { Table } 1 \text { Tidal prism through the inlets and over the tidal } \\
\text { divide, behind Terschelling. Amount in } 10^{6} \mathrm{~m}^{3} \text {. }\end{array}$} \\
\hline & & 1926 & 1933 & 2003 \\
\hline \multirow[t]{2}{*}{ Texel inlet } & Inflow & 870 & 990 & 1040 \\
\hline & Outflow & 995 & 1029 & 1090 \\
\hline \multirow[t]{2}{*}{ Eierlandse Gat } & Inflow & 153 & 145 & 204 \\
\hline & Outflow & 129 & 151 & 203 \\
\hline \multirow[t]{2}{*}{ Vlie } & Inflow & 944 & 1034 & 1076 \\
\hline & Outflow & 885 & 997 & 1011 \\
\hline Tidal divide & Inflow & 60 & 23 & 20 \\
\hline Terschelling & Outflow & 15 & 14 & 35 \\
\hline
\end{tabular}




\section{Ebb-tidal delta orientation}

The increase in tidal prisms also amplified the flow velocities through the inlets. The increase in tidal prism, in combination with small increase in tidal range in the inlet gorge, resulted in higher flow velocities. In 1926, the water level in the Texel inlet had a double peak at slack high water, whereas after closure, this double peak no longer occurred (Fig. 5). Additionally, in the Texel inlet, the phase between the water level and the discharge shifted with the peak in the water level subsequently lagging behind the peak in the discharge (Fig. 5, upper panel). The tidal wave changed from a wave with a propagating character to a wave with more of a standing character. As a result, the flood discharge will take place with relatively lower average water level than prior to closure, whereas the ebb velocities will take place at a higher water level. The net result is a larger increase in flood velocities than ebb velocities.
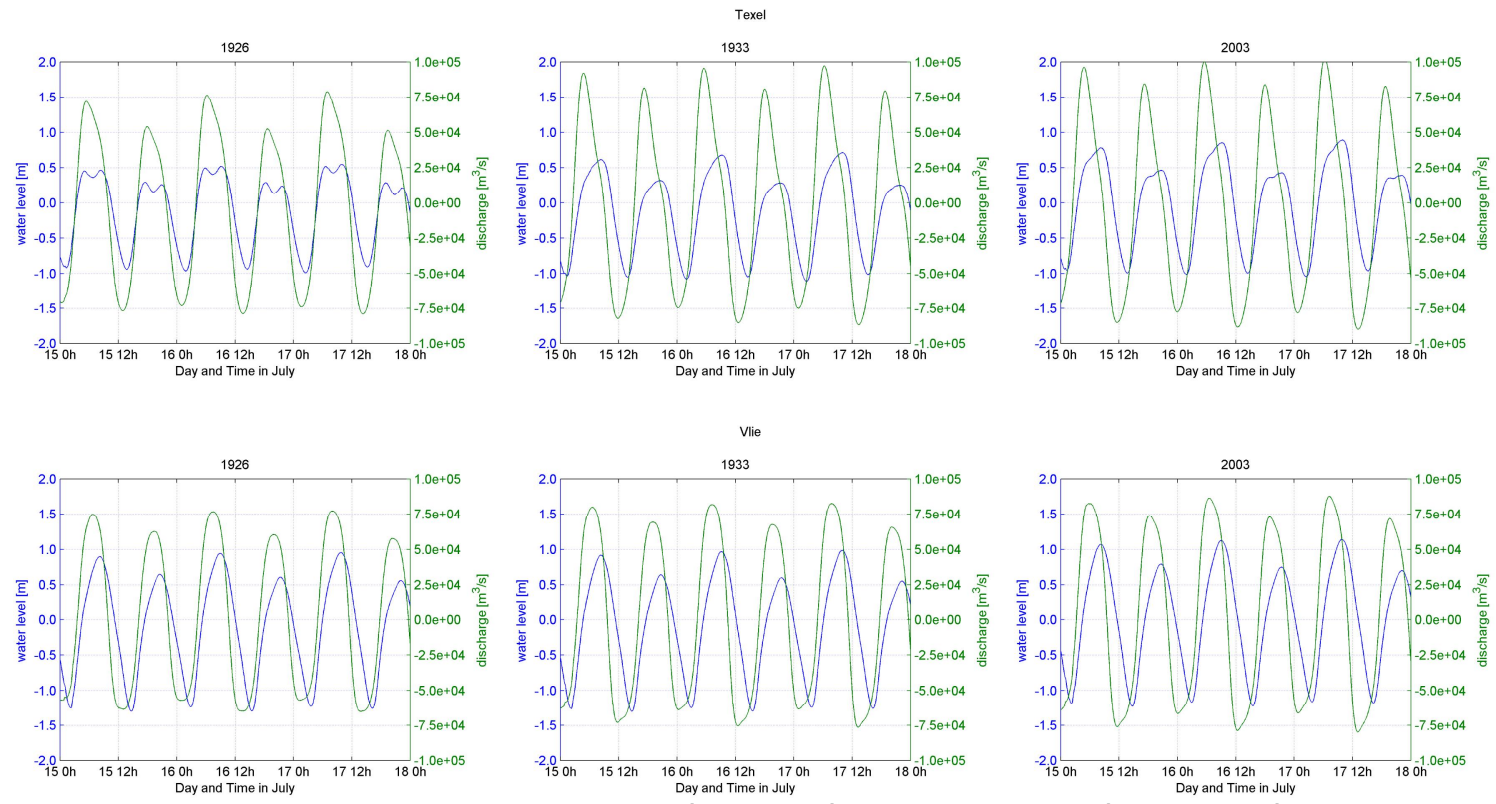

Figure 5. Water level and discharge in the Texel inlet (top panels) and in the Vlie inlet (lower panels) for the difference scenarios: pre-closure (left panel), after closure (middle panel) and present (right panel).

The phase shift between water level and discharge also has an effect on the orientation of the ebb-tidal delta. It indicates that the phase of the shore parallel currents in the North Sea compared to the flow through the inlet itself was affected. This is an important parameter for the ebb-tidal delta orientation, especially for ebb-tidal deltas where the tidal prism is large compared to the waves action (Sha 1989). In Fig. 6, different stages of a tidal cycle are plotted for the situation before closure (left panels) and after closure (1933, right panels). In the upper panel (a), the flow is just about to reverse in the Texel inlet in the pre-closure situation and has just reversed in the post-closure situation. This marks one of the most important changes: the moment of flow reversal in the Texel inlet, compared to the tidal stage, is occurring earlier after closure. In the first center panel (b), 3-hours later, a change in flow on the ebb-tidal delta takes place: after closure the highest flow velocities occur close to the North-Holland coast, in the SSW direction, whereas prior to closure, the highest flow velocities have a more SW direction. On the first lower panel (c), 3.5-hours later, the flow is reversing again and flow reversal occurs earlier in the post-closure situation. On the second upper panel (d), 2.5-hours later, it becomes clear that the outflow is more SSW directed after closure, compared to a WSW orientation prior to closure. The second middle panel (e), 2-hours later, the change in outflow direction is stronger and confirms the change in flow pattern of the panel above. Additionally, inside the basin, a change between the flow through the channels can be observed: after closure, more discharge is delivered by the channel along Texel compared to the second channel south of it, which is cut off due to the Afsluitdijk. In the situation before closure, the southern channel has a larger discharge compared to the pre-closure situation. On the second lower panel (f), 1.5-hour later, the tidal cycle is complete and the difference in flow reversal around low water is shown again. The shift in the tidal propagation through the inlet, versus the tidal propagation in the North Sea, is such that after closure 
outflow occurs more concurrently with the southward-directed shore parallel currents, whereas inflow occurs more concurrently with the northern-directed shore parallel currents.
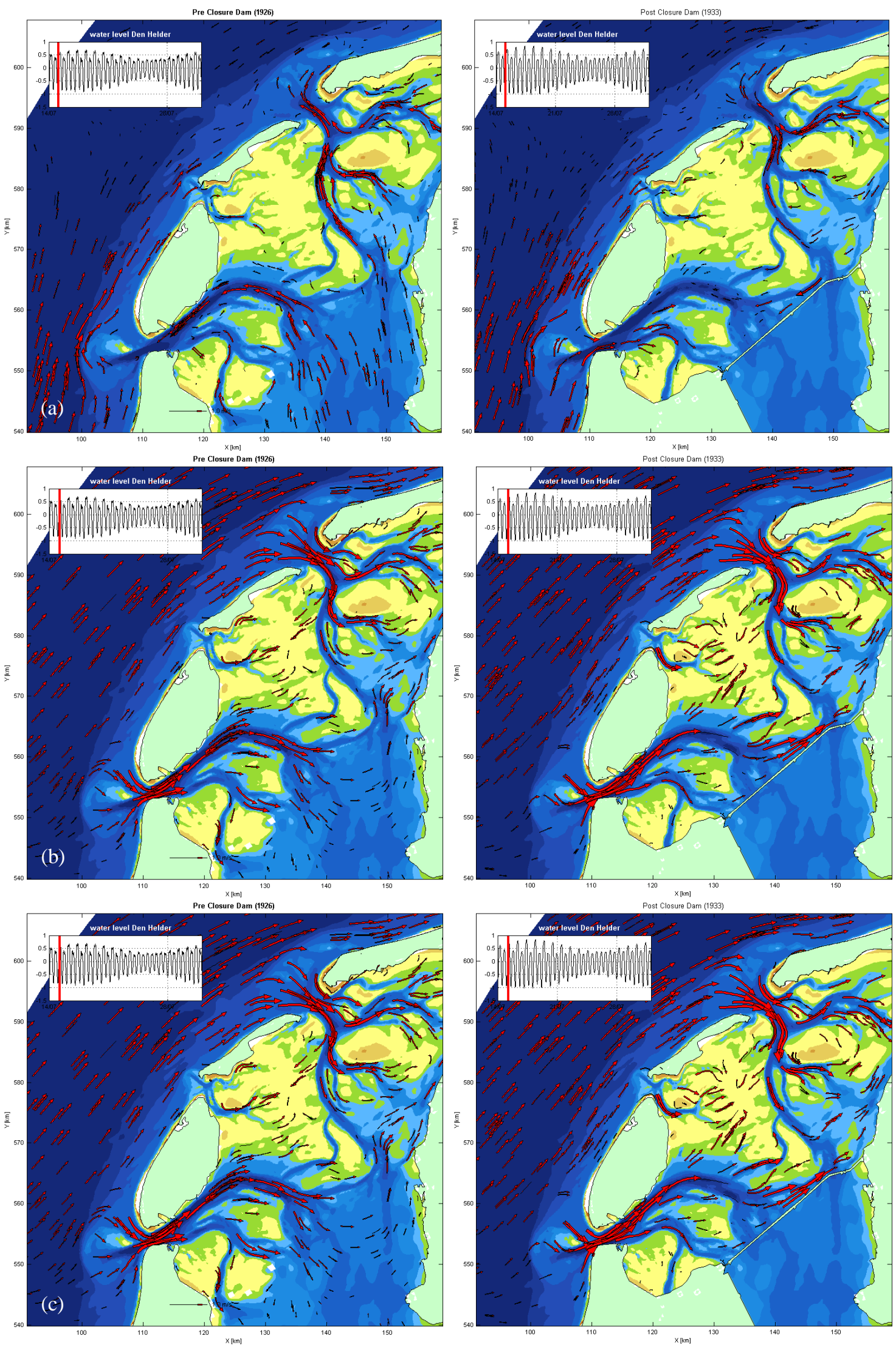

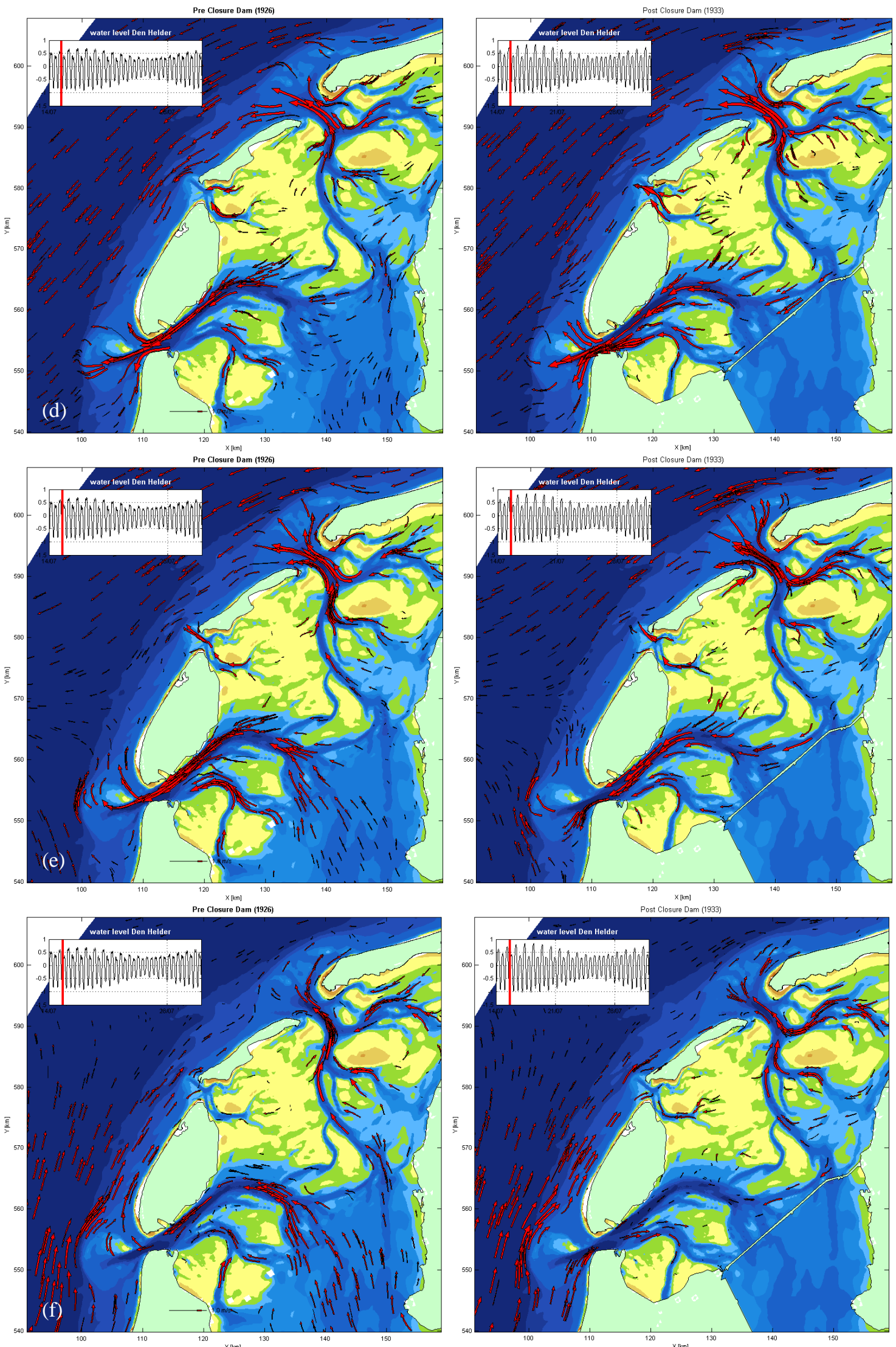

Figure 6. (a)-(f) Flow patterns in the pre-closure (left panels) and post-closure (1933) (right panels) scenarios during different stages in the tidal cycle. 
For the Vlie inlet, no pronounced shift between the horizontal and vertical tide is observed in the inlet, (Fig. 5). Comparing the flow fields for different moments within a tidal cycle, some smaller changes can be observed in the Vlie inlet (Fig. 6). The first upper panel (a) shows that after the closure the outflow is reduced at that moment. In the basin, after closure, the channel in the eastern part is mainly active, whereas the flow towards the Texel basin is less strong than prior to closure. In the first center panel (b), 3-hours later, no clear changes are observed. In the first lower panel (c), 3.5hours later, the inflow pattern is consistent with the outflow pattern. In the second upper panel (d), 2.5-hours later, no clear changes are observed. In the second center panel (e), 2-hours later, a difference in the flow in the basin can be seen, with more discharge delivered by the southern branches prior to closure compared to after closure. Additionally, more outflow on the ebb-tidal delta, close to the tip of Vlieland island, is predicted after closure. In the last panel (f), 1.5-hours later, the flow on the ebb-tidal delta is more northward-directed prior to closure than after closure. Averaged over one flood period during spring tide, the flow velocities in the Vlie inlet show no significant changes, indicating that there is minimal change in the flow through the inlet versus the shore parallel currents.

The Eierlandse Gat does not show any significant changes in flow patterns. In addition, there is no clear phase shift between the water level and discharge through the inlet.

\section{DISCUSSION AND CONCLUSIONS}

In this study, two hypotheses for ebb-tidal delta orientation changes have been investigated. For the first hypothesis to be valid, there must be a phase shift between the flow through the inlet and the tidal propagation in the North Sea. Analysis of the water level variation and discharge through the inlet, as well as the flow patterns throughout the tidal cycle, show that such a phase shift does occur in the Texel inlet, but is insignificant (or absent) in the Vlie inlet. The change in the ebb-tidal delta orientation of the Texel Inlet can thus possibly be explained by the theory of Sha (1989), but this does not apply for the Vlie Inlet. This means that there must be other factors determining the orientation of the ebb-tidal delta than the phase difference between the flow through the inlet and the tidal propagation along the coast. This is an indication that the second hypothesis can be true although the present analysis does not give direct proof. As a matter of fact, Elias and Van der Spek (2006) showed that this hypothesis can give an explanation for the changed orientation of the ebb-tidal delta of the Texel Inlet.

It can thus be concluded that both hypotheses can possibly explain the development of the ebbtidal delta of the Texel Inlet. It is thus still not clear in how far the two mechanisms have contributed to the change. For the Vlie Inlet the first hypothesis does not apply and whether the second hypothesis provides an explanation for the changed orientation of the ebb-tidal delta need still be investigated.

Further it is concluded that the closure of the Zuider Sea resulted in large increases in the tidal ranges, particularly along the Afsluitdijk. The increase was not instantaneous, but continued to grow after the closure due to altering bathymetry and sea level rise.

\section{REFERENCES}

Blok, M., Mol, J.W., 2001, Debietmeting Zeegat van Texel (in Dutch), Report 01.03, Rijkswaterstaat, Directie Noord-Holland, Informatiedienst Water, Ijmuiden.

Egbert, G.D., Bennett, A.F., Foreman, M.G.G., 1994. TOPEX/POSEIDON tides estimated using a global inverse model. Journal of Geophysical Research 99, C03005,doi:10.1029/2004JC002398.

Egbert, G.D., Erofeeva, S.Y., 2002. Efficient Inverse Modeling of Barotropic OceanTides. Journal of Atmospheric and Oceanic Technology 19, 183-204.

Elias, E.P.L., Stive, M.J.F., Bonekamp, J.G., Cleveringa, J., 2003. Tidal inlet dynamics in response to human intervention. Coastal Engineering Journal, 45(4): 629-658.

Elias, E.P.L., 2006, Morphodynamics of Texel Inlet, PhD thesis, Delft University of Technology.

Elias, E.P.L., Van der Spek, A.J.F., 2006. Long-term evolution of Texel Inlet and its ebb-tidal delta (The Netherlands). Marine Geology, 225: 5-21.

Elias, E.P.L., Van der Spek, A.J.F., Wang, Z.B., De Ronde, J.G., 2012. Morphodynamic development and sediment budget of the Dutch Wadden Sea over the last century, Netherlands Journal of Geosciences, accepted. 
Hayes, M. O. (1979). "Barrier Island morphology as a function of tidal and wave regime", Barrier Islands: From the Gulf of St Lawerence to the Gulf of Mexico, S. P. Leatherman, ed., Academic Press, New York, 1-27.

Klok, B., Schalkers, K.M., 1980, De veranderingen in de Waddenzee ten gevolge van de afsluiting van de Zuider Zee (in Dutch), Report 78.H238. Rijkswaterstaat, The Hague.

Lorentz, H.A., 1926, Verslag Staatscommissie Zuiderzee 1918-1926 (in Dutch), Report, Rijkswaterstaat, The Hague.

Oertel, G. F. (1988). "Processes of sediment exchange between tidal inlets, ebb deltas and barrier islands", lecture notes on coastal and estuarine studies, Vol. 29; Hydrodynamics and sediment dynamics of tidal inlets, L.W. D.G. Aubrey and L. Weishar, eds., Springer-Verlag, New York.

Oost, A.P., Kleine Punte, P.A.H., (2004). Autonome morfologische ontwikkeling westelijke Waddenzee. Report RIKZ/ 2004.021. Rijkswaterstaat, The Hague.

Rietveld, C.F.W., 1962, The natural development of the Wadden Sea after the closure of the Zuider Sea, Proc. of the $8^{\text {th }}$ International Conference on Coastal Engineering, Mexico City, 765-781.

Sha, L.P., 1989, Cyclic morphologic changes on the ebb-tidal delta, Texel Inlet, Wadden Sea, The Netherlands, Geologie en Mijnbouw, 68, 35-48.

Walton, T.L. and Adams, W.D., 1976, Capacity of inlet outer bars to store sand, Proc. of the $15^{\text {th }}$ International Conference on Coastal Engineering, Honolulu, 303-325. 